\title{
Enteroglial-derived S100B protein integrates bacteria-induced Toll-like receptor signalling in human enteric glial cells
}

\author{
Fabio Turco, ${ }^{1}$ Giovanni Sarnelli, ${ }^{1}$ Carla Cirillo, ${ }^{1,2}$ |laria Palumbo, ${ }^{1}$ \\ Francesco De Giorgi, ${ }^{1}$ Alessandra D'Alessandro, ${ }^{1}$ Marcella Cammarota, ${ }^{3}$ \\ Mariateresa Giuliano, ${ }^{3}$ Rosario Cuomo ${ }^{1}$
}

\begin{abstract}
- Additional material is published online only. To view please visit the journal online (http://dx.doi.org/10.1136/ gutjnl-2012-302090).

${ }^{1}$ Department of Clinical and Experimental Medicine, 'Federico II' University of Naples, Naples, Italy ${ }^{2}$ Laboratory for Enteric Neuroscience (LENS), TARGID, $\mathrm{KU}$ Leuven, Leuven, Belgium ${ }^{3}$ Department of Experimental Medicine, Biotechnology and Molecular Biology section, Seconda Università di Napoli, Naples, Italy
\end{abstract}

\section{Correspondence to} Professor Rosario Cuomo, Department of Clinical and Experimental Medicine, Gastroenterological Unit, 'Federico II' University of Naples, Via Sergio Pansini 5, Naples 80131, Italy; rcuomo@unina.it

Received 20 January 2012 Revised 23 November 2012 Accepted 4 December 2012

\footnotetext{
To cite: Turco F, Sarnelli $G$, Cirillo C, et al. Gut Published Online First: [please include Day Month Year] doi:10.1136/gutjnl2012-302090
}

\begin{abstract}
Objective Enteric glial cells (EGC) have been

suggested to participate in host-bacteria cross-talk, playing a protective role within the gut. The way EGC interact with microorganisms is still poorly understood. We aimed to evaluate whether: EGC participate in hostbacteria interaction; S100B and Toll-like receptor (TLR) signalling converge in a common pathway leading to nitric oxide (NO) production.

Design Primary cultures of human EGC were exposed to pathogenic (enteroinvasive Escherichia coli; EIEC) and probiotic (Lactobacillus paracasei F19) bacteria. Cell activation was assessed by evaluating the expression of cFos and major histocompatibility complex (MHC) class II molecules. TLR expression in EGC was evaluated at both baseline and after exposure to bacteria by real-time PCR, fluorescence microscopy and western blot analysis. S100B expression and NO release from EGC, following exposure to bacteria, were measured in the presence or absence of specific TLR and S100B pathway inhibitors.
\end{abstract}

Results EIEC activated EGC by inducing the expression of CFos and MHC II. EGC expressed TLR at baseline. Pathogens and probiotics differentially modulated TLR expression in EGC. Pathogens, but not probiotics, significantly induced S100B protein overexpression and NO release from EGC. Pretreatment with specific inhibitors of TLR and S100B pathways abolished bacterial-induced NO release from EGC.

Conclusions Human EGC interact with bacteria and discriminate between pathogens and probiotics via a different TLR expression and NO production. In EGC, NO release is impaired in the presence of specific inhibitors of the TLR and S100B pathways, suggesting the presence of a novel common pathway involving both TLR stimulation and S100B protein upregulation.

\section{INTRODUCTION}

The gastrointestinal tract is the main gateway between the outside environment and the inner body. It acts as the first defence barrier against microorganisms and its ability to discriminate between harmful or healthy bacteria is pivotal to preserve the intestinal homeostasis. The preservation of the intestinal environment is ensured by the efficient host-bacteria interaction and depends on a complex interplay between the microbiota, the innate immune system and several cell types resident

\section{Significance of this study}

What is already known on this subject?

- EGC regulate intestinal homeostasis and are involved in intestinal inflammation.

- Glial cells in the central nervous system express TLR.

- Human-derived EGC produce NO in response to exogenous proinflammatory stimuli.

What are the new findings?

- Human-derived EGC express TLR.

- TLR expression in human-derived EGC is differently modulated by pathogenic and probiotic bacteria.

- Pathogenic, but not probiotic bacteria, stimulate the release of NO in human-derived EGC via the involvement of both TLR and S100BIRAGE.

How might it impact on clinical practice in the foreseeable future?

- This study, highlighting the role of human-derived EGC in the host-bacteria interaction, adds further data in the field of bacteriotherapy. In addition, as these cells can respond adequately to bacterial insults (ie, releasing NO), they might be regarded as a novel and potentially pharmacological target to modulate nitrosative stress within the gut.

in the lamina propria. ${ }^{1}$ Based on recent evidences, enteric glial cells (EGC) seem to cooperate with other cells (ie, immune and epithelial cells) to maintain homeostasis in the intestinal milieu. ${ }^{2}{ }^{3}$ In particular, EGC control epithelial barrier functions by inhibiting intestinal epithelial cell proliferation and by reducing epithelial permeability via the release of glial-derived factors, such as transforming growth factor $\beta$ and S-nitrosoglutathione, ${ }^{4} 5$ as demonstrated in in-vitro and ex-vivo models of Shigella flexneri invasion. ${ }^{6}{ }^{7}$ An emerging concept from these preliminary reports is that EGC may protect the host against invading pathogens, probably contributing to the regulation of the host-bacteria interaction. However, whether human EGC are activated 
by bacteria and which pathways are involved in the EGC-bacteria interaction have not yet been investigated.

Data from the central nervous system indicate that astrocytes, the EGC equivalent in the brain, are directly involved in the regulation of host-bacteria interaction by acting as resident antigenpresenting cells and via the expression of Toll-like receptors (TLR). ${ }^{8}{ }^{9}$ Barajon et $a l^{10}$ also reported that TLR3, TLR4 and TLR7 are expressed by enteric neurons and glial cells in mouse intestine. It is also conceivable that human EGC express TLR. Although these observations indicate that enteric glia might be activated by bacteria, they do not provide any explicit evidence of their involvement in the crosstalk with intestinal microbiota. Whether bacteria are able to modulate TLR expression on EGC and what their putative involvement may be in this interaction remain to be elucidated.

TLR stimulation leads to the expression of a broad number of genes involved in the innate and adaptive immunity against pathogens, including inducible nitric oxide synthase (iNOS). ${ }^{11} 12$ Nitric oxide (NO) is a pro-inflammatory molecule that enhances antibacterial response. ${ }^{13}$ We have previously reported that, in humans, EGC-derived S100B protein regulates NO production in intestinal mucosa and that this mechanism is mediated by interaction with the receptor for advanced glycation endproducts (RAGE), ${ }^{14}{ }^{15}$ which is also involved in the TLR signalling pathway. ${ }^{16}$ S100B-mediated NO production has been observed in intestinal biopsies of patients with coeliac disease and ulcerative colitis. Whether similar mechanisms also play a role in bacteria-induced EGC activation is unknown.

In this study, we aimed first to investigate the ability of human EGC to interact directly with bacteria and, second, to evaluate whether pathogenic or probiotic bacteria are able to modulate TLR expression on EGC differentially. We also tested whether EGC respond to bacteria by releasing NO and what the pathways involved in this response may be.

\section{MATERIALS AND METHODS}

\section{EGC isolation, culture, purification and characterisation}

Primary cultures of EGC were obtained according to the method previously described by our group. ${ }^{17}$ Briefly, specimens of human small bowel were taken from patients undergoing surgery for colorectal cancer (four men, mean age $57 \pm 4$ years; four women, mean age $59 \pm 6$ years). All procedures were approved by the ethics committee of the 'Federico II' University of Naples (protocol no 106/2010). After removal, the tissue was dissected to expose the myenteric plexus. After digestion $\left(30 \mathrm{~min}\right.$ at $37^{\circ} \mathrm{C}$ in an enzymatic solution containing protease and collagenase $)^{18}$ ganglia were cultured with $1 \mathrm{ml}$ of DMEM-F12 supplemented with 10\% heat-inactivated fetal calf serum, $1 \%$ antibiotic-antimycotic solution and $1 \%$ sodium pyruvate (all reagents from Sigma) and kept in an incubator at $37^{\circ} \mathrm{C}$, continuously gassed with $95 \%$ oxygen $-5 \%$ carbon dioxide.

After 3-4 weeks, EGC were purified using Dynal-Magnet (Miltenyi Biotec GmbH, Bergisch Gladbach, Germany), according to the manufacturer's instructions and to the method we have previously described. ${ }^{17} 19$ The separation step with dynabeads was performed twice in order to eliminate residual fibroblasts/smooth muscle cells within the culture. The resulting EGC enriched cultures $\left(\sim 500 \times 10^{3}\right.$ cells $\left./ \mathrm{ml}\right)$ were characterised by immunofluorescence and, as previously reported, contaminating cells were virtually absent. ${ }^{17}$ After an average of five passages, EGC were exposed to different experimental conditions, as listed below. EGC isolated from each tissue served for a single set of experiments.

\section{Bacterial strains}

To evaluate the interaction of EGC with different strains of bacteria, enteroinvasive Escherichia coli (EIEC), a Gram-negative bacteria, was chosen for its deleterious effects on the gastrointestinal tract, ${ }^{20}$ while Lactobacillus paracasei ssp paracasei F19 (LP F19), a Gram-positive bacteria, was chosen for its beneficial effect. ${ }^{21}$ EIEC (ATCC, Rockville, Maryland, USA) was cultured at $37^{\circ} \mathrm{C}$ under anaerobic conditions in TSB (Oxoid, Cambridge, UK). LP F19 (kindly provided by Arla Foods, Stockholm, Sweden, international publication no WO 99/29833) was grown in the same conditions in MRS broth (Oxoid). Bacterial stocks were prepared from high cell density fermentation and cultures were counted and diluted in MRS agar $(2 \%)$ or TSB agar (2\%) to correlate optical density (OD; at A600 nm) to cell concentrations. An OD of 1 was adjusted to $1.9 \times 10^{9}$ colony-forming units/ml for EIEC and to $3.4 \times 10^{8}$ colony-forming units/ml for LP F19. The EGC/bacteria ratio, at the time of infection, was determined by measuring the OD of bacterial culture and then calculating the appropriate volume to add to EGC.

\section{Cell stimulation}

To investigate TLR expression in EGC, pathogen EIEC and probiotic strain LP F19 were added to the culture medium of 7 days EGC enriched cultures. Based on our preliminary experiments, we chose to expose EGC to a low bacterial charge (bacteria/EGC ratio was 1/10), for 6 and $24 \mathrm{~h}$, to minimise cell mortality (data on cell mortality are reported as supplementary data, available online only). Control experiments (basal) were performed using the medium alone, and $\mathrm{pH}$ values of the medium were measured before and after bacterial infection (see supplementary data, available online only). Experiments were realised using both the viable and the heat-inactivated bacteria, or with the bacterial-derived soluble factors. Heat inactivation was effected by heating the bacterial suspension at $100^{\circ} \mathrm{C}$ for $1 \mathrm{~h}$. Soluble factor-containing media were generated by incubating bacteria in DMEM-F12 at $37^{\circ} \mathrm{C}$ for $2 \mathrm{~h}$; media were then centrifuged twice and supernatants were filtered $(0.2 \mathrm{~mm})$.

To prove the effective functionality of TLR on EGC, we exposed EGC for $24 \mathrm{~h}$ to both the TRL2 agonist zymosan $(100 \mu \mathrm{g} / \mathrm{ml}$; Sigma, Milan, Italy), TLR3 agonist poly (I:C) (50 $\mu \mathrm{g} / \mathrm{mll}$; Imgenex Corp., San Diego, California, USA), TLR4 agonist lipopolysaccharide $(10 \mu \mathrm{g} / \mathrm{ml}$; Sigma), in the presence or absence of MyD88 homodimerisation-blocking peptide $(20 \mu \mathrm{g} / \mathrm{ml}$; Imgenex), added $24 \mathrm{~h}$ before exposure to agonists; then we analysed the protein expression of nuclear factor $\kappa \mathrm{B}(\mathrm{NF}-\kappa \mathrm{B})$ (p50 subunit).

In a second set of experiments, S100B expression and NO production were evaluated after $24 \mathrm{~h}$ in the presence or absence of either S100B-blocking antibody (AbCam, Cambridge, Massachusetts, USA), ${ }^{22}$ RAGE-blocking antibody (R\&D Systems, Minneapolis, Minnesota, USA), ${ }^{23}$ or MyD88 homodimerisationblocking peptide (Imgenex), ${ }^{24}$ each added $24 \mathrm{~h}$ before EGC infection with bacteria.

\section{RNA isolation, reverse transcription and quantitative real-time PCR}

RNA was extracted from EGC using trizol reagent (Invitrogen SRL, San Giuliano Milanese, Italy) according to the manufacturer's instructions. The RNA quality and concentration was determined using a nanodrop spectrophotometer (Celbio, Milan, Italy). Extracted RNA was treated with a DNA-free kit (Ambion, Austin, Texas, USA), according to the manufacturer's 
instructions. Complementary DNA synthesis from Dnasedigested RNA was performed using the iScript cDNA synthesis kit (Bio-Rad Laboratories, Hercules, California, USA).

Quantitative real-time PCR for TLR messenger RNA was performed on an iCycler instrument (Bio-Rad), using iQ Syber Green mastermix (Bio-Rad). ${ }^{25}$ Primers were taken either from sequences published elsewhere, ${ }^{26}{ }^{27}$ or from Beacon Designer software (Premier Biosoft, Palo Alto, California, USA) and selected to anneal to adjacent exons. See supplementary table S1 (available online only) for primer sequences. After each reaction, a melting curve was used to confirm the specificity of the PCR products. The $\Delta \Delta \mathrm{C}_{\mathrm{T}}$ method was used for quantisation of TLR mRNA expression in stimulated cells compared to unstimulated cells, ${ }^{28}$ where the cycle threshold $\left(\mathrm{C}_{\mathrm{T}}\right)$ is the cycle at which the signal detected is significantly above the background signal, $\Delta \mathrm{C}_{\mathrm{T}}$ is the difference between the $C_{T}$ of the TLR gene of interest and the $\mathrm{C}_{\mathrm{T}}$ of the endogenous control gene $\beta$-actin and $\Delta \Delta \mathrm{C}_{\mathrm{T}}=\Delta \mathrm{C}_{\mathrm{T}}$ TREATMENT $-\Delta \mathrm{C}_{\mathrm{T} \text { BASAL}}$. Because of differing primer efficiencies, the $C_{T}$ was calculated normalising efficiency values to that of $\beta$-actin. Data are expressed as fold of increase in TLR mRNA expression in EGC stimulated with bacteria, compared to EGC cultured in medium alone (basal), after normalisation to $\beta$-actin mRNA. Each experiment was performed in triplicate. For comparative purposes, as previously reported in the literature, ${ }^{29}$ estimation of the absolute mRNA levels for TLR under basal conditions was made categorising $\Delta \mathrm{C}_{\mathrm{T}}$ values for each TLR into different ranges of expression: high expression correlating with small $\Delta \mathrm{C}_{\mathrm{T}}(\leq 5)$, intermediate expression with $5<\Delta \mathrm{C}_{\mathrm{T}}>15$, low or very low expression with $\Delta \mathrm{C}_{\mathrm{T}} \geq 15$ and $\Delta \mathrm{C}_{\mathrm{T}} \geq 40$ cycles equivalent to undetected.

\section{Protein extraction and western immunoblot analysis}

We analysed protein expression of three specific TLR, namely TLR2, TLR3 and TLR4, after a 24 h-challenge with bacteria. We chose to characterise these TLR better because TLR2 and TLR4 recognise mainly Gram-positive and Gram-negative bacteria, ${ }^{30}$ respectively, and TLR3 has the highest protein expression, among all TLR, in astrocytes. ${ }^{29} 31$ We also focused our investigation on these TLR because TLR2 signalling is restricted to the classic MyD88-dependent pathway, TLR3 to the MyD88independent pathway and TLR4 is capable of signalling through both ways. ${ }^{30}$ To perform western blot analysis, EGC were homogenised in ice-cold hypotonic lysis buffer. The protein concentration was determined by a protein assay kit (Bio-Rad). For immunoblotting analysis, equivalent amounts of each sample were denatured, separated on a sodium dodecyl sulfatepolyacrylamide gel and transferred to a nitrocellulose membrane (Amersham, Milan, Italy). The membranes were blocked for $2 \mathrm{~h}$ at room temperature in $10 \%$ milk buffer and were incubated overnight at $4^{\circ} \mathrm{C}$ with rabbit anti-TLR2 (1:500 vol/vol dilution; Santa Cruz Biotechnology, Santa Cruz, California, USA), mouse anti-CD283 (TLR3) (1:500; BD Biosciences, Franklin Lakes, New Jersey, USA), rabbit anti-TLR4 (1:500; AbCam), mouse anti-major histocompatibility complex (MHC) class II (1:500; AbCam), or mouse anti-S100B (1:1000; AbCam) antibodies. For experiments with TLR agonists, we used mouse anti-NF-кBp50 (1:250; Santa Cruz Biotechnology). To obtain nuclear extracts, cells were homogenised in lysis buffer $(10 \mathrm{mM}$ HEPES $\mathrm{pH} 7.8$, $10 \mathrm{mM} \mathrm{KCl}, 2 \mathrm{mM} \mathrm{MgCl} 2,1 \mathrm{mM}$ dithiothreitol, $0.1 \mathrm{mM}$ EDTA and $0.1 \mathrm{mM}$ phenylmethylsulfonyl fluoride). To the homogenate was added $125 \mu \mathrm{l}$ of $10 \%$ nonidet P-40 solution and the mixture was then centrifuged at $14000 \mathrm{~g}$. The pellet containing nuclei was washed once with $0.4 \mathrm{ml}$ of the same buffer plus $25 \mu \mathrm{l}$ of $10 \%$ nonidet P-40, centrifuged, and resuspended in $100 \mu \mathrm{l}$ of nuclear extraction buffer (50 mM HEPES pH 7.8, $50 \mathrm{mM} \mathrm{KCl,}$ $0.3 \mathrm{M} \mathrm{NaCl}, 0.1 \mathrm{mM}$ EDTA, $1 \mathrm{mM}$ dithiothreitol, $0.1 \mathrm{mM}$ phenylmethylsulfonyl fluoride and $10 \%$ glycerol). After incubation at $4^{\circ} \mathrm{C}$ for $20 \mathrm{~min}$, the mixtures were centrifuged for $5 \mathrm{~min}$ at $14000 \mathrm{~g}$. Subsequently, membranes were incubated for $2 \mathrm{~h}$ at room temperature with the specific secondary antibody conjugated to horseradish peroxidase (AbCam). Western blots were analysed by scanning densitometry (GS-700 imaging densitometer; Bio-Rad) and the results were expressed as OD (arbitrary units; $\mathrm{mm}^{2}$ ).

\section{Immunocytochemistry}

EGC were fixed at room temperature with freshly prepared paraformaldehyde $4 \%$. After being washed in $0.1 \mathrm{M}$ PBS, cells were processed, as to block non-specific binding sites, with 0.1 M PBS with Triton-X and 10\% goat serum (blocking buffer) for $2 \mathrm{~h}$ at room temperature. Subsequently, for doubleimmunofluorescence staining, EGC were exposed overnight at $4^{\circ} \mathrm{C}$ to primary antibodies: mouse anti-S100B $(1: 1000)$ or rabbit anti-glial fibrillary acidic protein (GFAP) (1:1000; AbCam)two specific markers of EGC ${ }^{2} 1432$-were used in combination with rabbit anti-TLR2 (1:1000; Santa Cruz Biotechnology), mouse anti-CD283 (TLR3) (1:1000; BD Biosciences), rabbit anti-TLR4 (1:1000; AbCam), respectively, or with mouse anti-MHC-II $(1: 1000 ; \mathrm{AbCam})$ or rabbit anti-cFos $(1: 1000$; AbCam) to assess cell activation. Nuclei were stained with Hoechst. Negative controls were carried out by omitting the primary antibodies. To test any non-specific antigen-binding sites, additional experiments were performed using specific isotype antibody controls (Imgenex Corp), at the same concentration as the primary antibodies. After incubation, cells were rinsed in $0.1 \mathrm{M}$ PBS and incubated at room temperature for $1 \mathrm{~h}$ with the specific secondary antibody diluted in blocking buffer (Alexa Fluor 546 goat anti-mouse or Alexa fluor 488 goat antirabbit; Invitrogen). Fluorescence was visualised on a Nikon Eclipse E600 microscope (excitation filters Nikon 510-560 and Nikon 470-490). Images were captured using a Nikon Coolpix digital camera connected to the microscope, cropped using Adobe Photoshop (Adobe Systems, San Jose, California, USA) making minimal alterations (minor adjustments to brightness and contrast) and finally transferred to Microsoft Powerpoint for the creation of the figure sets. Fluorescence quantisation was performed using ImageJ software V.1.42 $\mathrm{q}^{33^{34}}$ (National Institutes of Health).

\section{Statistical analysis}

Statistical analysis was performed with analysis of variance and multiple comparisons with Bonferroni's test. Data presented are mean \pm SD of $n$ experiments. The level of statistical significance was set at $\mathrm{p}<0.05$.

\section{RESULTS}

\section{Purity of isolated EGC}

Data on purity of EGC cultures are reported as supplementary material (available online only) and have been reported previously. $^{17}$

\section{EGC activation after exposure to bacteria}

Figure 1 shows that, after $24 \mathrm{~h}$ exposure to EIEC, EGC expressed MHC-II molecules (f), which were not expressed in basal conditions (b). In parallel, $24 \mathrm{~h}$ exposure to EIEC induced the expression of the nuclear protein cFos (n)-considered to be a cell activation marker, ${ }^{35}$ which was not expressed in basal conditions (j). MHC-II and cFos positivity was specifically localised 
A

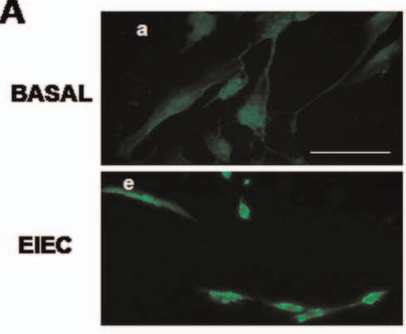

GFAP

B

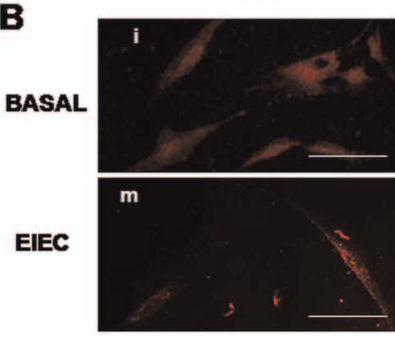

S100B

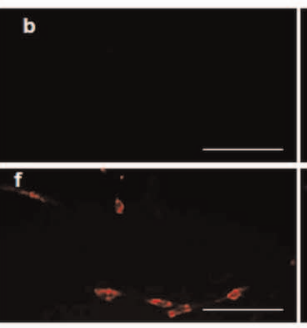

MHCclass II
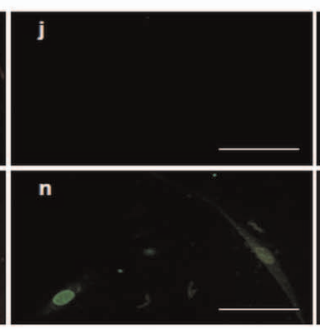

cFos
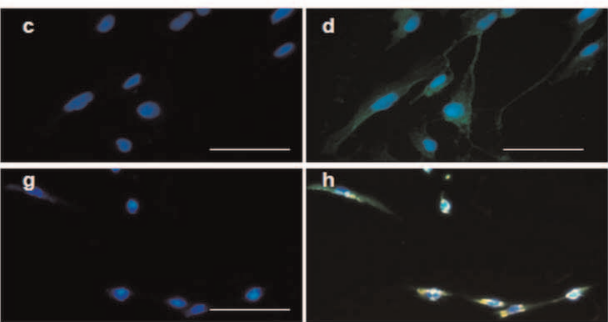

HOECHST
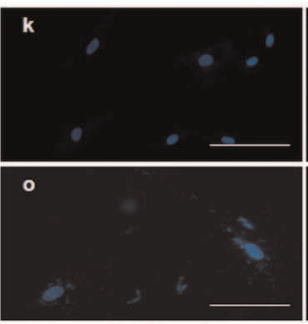

HOECHST

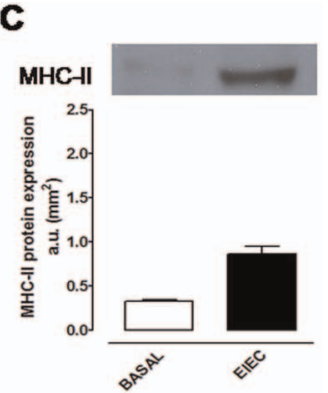

Figure 1 Enteric glial cell (EGC) activation following bacterial stimulation. (A) Immunocytochemistry showing major histocompatibility complex (MHC) class II expression in EGC after $24 \mathrm{~h}$ exposure to the pathogen enteroinvasive Escherichia coli (EIEC). (B) Immunocytochemistry showing cFOS expression in EGC after $24 \mathrm{~h}$ exposure to the pathogen EIEC. Immunofluorescence staining revealed both MHC-II (f; red) and cFOS (n; green) expression in EGC ( $a$, e: glial fibrillary acidic protein, green and $\mathrm{i}, \mathrm{m}$ : S100B, red) after exposure to EIEC compared to unstimulated EGC (b and j, respectively). Nuclei were stained with Hoechst $(c, g, k, 0)$. Panels $d, h, I$ and $p$ : merged. Note that in panel $p$ cFOS co-localise with Hoechst. Pictures are representative of $n=5$ independent immunofluorescence assays. Scale bars: $10 \mu \mathrm{m}(a-d, m-p) ; 100 \mu \mathrm{m}(\mathrm{e}-\mathrm{l})$. (C) Western blot analysis showing the protein expression of MHC-II in EIEC-stimulated compared to unstimulated EGC. The expression of MHC-II in cell homogenates is shown in the upper panel, whereas the densitometric analysis of corresponding bands is represented in the graph and expressed as $\mathrm{mm}^{2}$ (arbitrary units). Each bar shows the mean $\pm S D$ of $n=3$ independent experiments. ${ }^{*} p<0.05$ versus basal.

and restricted to GFAP and S100B-positive EGC. We were not able to detect MHC-II or cFos expression after $6 \mathrm{~h}$ exposure to EIEC (data not shown). Western blot data, normalised on the specific glial marker, GFAP, confirmed that MHC-II expression was induced by EIEC $(+160 \% \pm 12$ increase vs basal; $\mathrm{p}<0.05)$ (figure 1C).

\section{Cell mortality and $\mathrm{pH}$ values after exposure to bacteria}

Data on cell mortality and $\mathrm{pH}$ values are reported as supplementary data (available online only).

\section{Baseline TLR mRNA expression in EGC}

mRNA analysis by real-time PCR revealed that EGC physiologically express TLR. Figure 2 shows the baseline expression of TLR. Based on the literature, ${ }^{29}$ TLR expression was categorised into different ranges of expression, from high to rare. Whereas TLR3 and TLR5 were expressed at an intermediate level $\left(5<\Delta \mathrm{C}_{\mathrm{T}}>15\right)$, other TLR were expressed at a very low level compared to the housekeeping $\beta$-actin gene, with TLR7 and TLR9 being the less expressed.

\section{Modulation of TLR mRNA expression induced by}

\section{$6 \mathrm{~h}$ exposure to pathogen and probiotic bacteria}

Compared to basal conditions and after $6 \mathrm{~h}$ challenge with bacteria, TLR1 mRNA expression was significantly upregulated by both EIEC and LP F19 $(+9.4 \pm 1.0$ and $+10.3 \pm 1.0$-fold increase vs basal; $\mathrm{p}<0.01)$, as were TLR3 $(+24.1 \pm 3.1$ and +6.3 \pm 0.5 -fold increase vs basal; $\mathrm{p}<0.01)$ and TLR4 $(+22.3 \pm 3.3$ and $+26.0 \pm 2.2$-fold increase vs basal; $p<0.01$ ). Conversely, TLR5 expression was significantly upregulated only by LP F19 $(+2.0$ \pm 0.5 -fold increase vs basal; $\mathrm{p}<0.01$ ) (figure $3 \mathrm{~A}$ ).

The analysis of differences between viable pathogenic and probiotic bacteria showed that after $6 \mathrm{~h}$ EIEC induced a significantly higher TLR3 expression compared to LP F19 (+3.8 \pm 2.1 -fold increase vs LP F19; $\mathrm{p}<0.01$ ). Conversely, compared to LP F19, EIEC induced a significantly lower expression of TLR5 $(-9.9 \pm 2.0$-fold decrease vs LP F19; $<<0.01)$ and TLR7 $(-16.3 \pm 3.1$-fold decrease vs LP F19; $\mathrm{p}<0.01)$ (figure $3 \mathrm{~A}$ ).

Modulation of TLR mRNA expression induced by $24 \mathrm{~h}$-exposure to pathogen and probiotic bacteria Analysis of TLR mRNA levels in EGC stimulated with viable pathogenic or probiotic bacteria revealed that, compared to

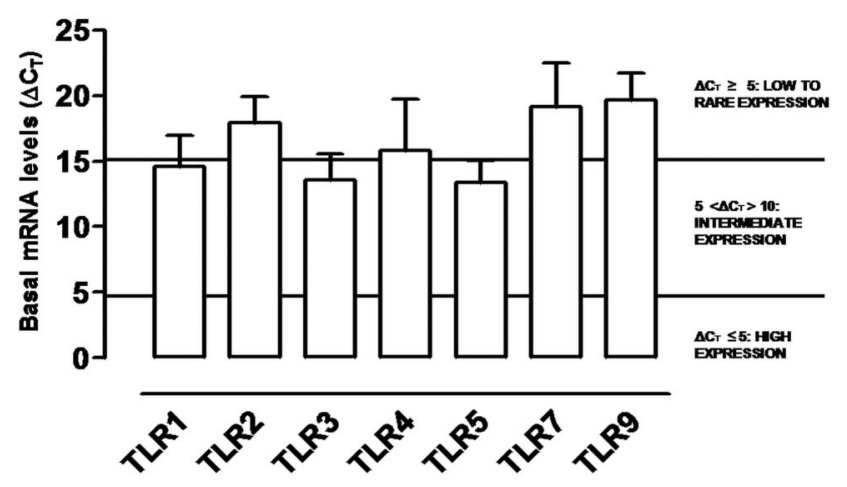

Figure 2 Baseline Toll-like receptors (TLR) mRNA expression on enteric glial cells (EGC) by quantitative real-time PCR. mRNA analysis revealed that EGC physiologically express all the TLR analysed. Baseline mRNA levels for TLR were estimated by determining the difference between the $C_{T}$ of the TLR gene of interest and the $C_{T}$ of the endogenous control gene, $\beta$-actin. $\Delta C_{T}$ values for each TLR were categorised into different expression ranges, as described in the Materials and methods section. In this graph, the highest is the $\Delta C_{T}$ value, the lowest is the expression. Each bar indicates the mean \pm SD of $\mathrm{n}=8$ independent determinations. 
basal conditions, TLR2 expression was significantly upregulated by both EIEC and LP F19 $(+4.1 \pm 0.1$ and $+2.7 \pm 0.1$-fold increase vs basal; $\mathrm{p}<0.01)$, TLR3 expression was significantly upregulated only by EIEC $(+10.0 \pm 1.0$-fold increase vs basal; $\mathrm{p}<0.01)$, as were TLR7 $(+8.0 \pm 0.2$-fold increase vs basal; $\mathrm{p}<0.01)$ and TLR9 $(+8.8 \pm 1.7$-fold increase vs basal; $\mathrm{p}<0.01)$. TLR5 mRNA expression was significantly upregulated only by LP F19 (+29.3 \pm 8.1 -fold increase vs basal; $p<0.01)$ (figure $3 \mathrm{~B}$ ).

The analysis of differences between pathogenic and probiotic bacteria showed that, compared to LP F19, EIEC induced a significantly higher expression of TLR2 $(+1.5 \pm 0.1$-fold increase vs LP F19; $\mathrm{p}<0.01)$, TLR3 $(+6.25 \pm 0.9$-fold increase vs LP F19; $\mathrm{p}<0.01)$, TLR7 $(+4.7 \pm 0.5$-fold increase vs LP F19; $\mathrm{p}<0.01)$ and TLR9 $(+8.0 \pm 1.2$-fold increase vs LP F19; $\mathrm{p}<0.01)$. Conversely, EIEC induced a lower TLR5 expression than LP F19 $(-10.1 \pm 2.4$-fold decrease vs LP F19; $\mathrm{p}<0.01)$ (figure 3B).

\section{Different TLR mRNA expression induced by heat-inactivated pathogens and probiotics}

In order to gain more mechanistic insights, we also analysed TLR mRNA expression after the incubation of EGC with heat-inactivated pathogens and probiotics. Both the heat-inactivated LP F19 and EIEC induced a different TLR mRNA expression than the viable bacteria.

After $6 \mathrm{~h}$ with the heat-inactivated EIEC, TLR2, TLR7 and TLR9 expression was virtually undetectable (less than 0.1-fold increase compared to basal) and only TLR5 expression was significantly downregulated by heat-inactivated EIEC $(-10.3 \pm 0.9$-fold decrease vs basal; $\mathrm{p}<0.01$ ) (figure $4 \mathrm{~A}$ ). After $24 \mathrm{~h}$, TLR2 expression remained lower than basal $(-3.8 \pm 0.3$-fold decrease vs basal; $\mathrm{p}<0.01$ ), while TLR7 and TLR9 expression did not significantly differ from basal conditions. Conversely, heat-inactivated EIEC significantly upregulated TLR3 (+18.3 \pm 1.5 -fold increase vs basal; $\mathrm{p}<0.01)$ and TLR4 expression $(+6.0 \pm 0.6$-fold increase vs basal; $\mathrm{p}<0.01$ ) (figure $4 \mathrm{~B}$ ). The analysis of differences between viable and heat-inactivated EIEC showed that, after $6 \mathrm{~h}$, TLR expression induced by viable EIEC was significantly different from heat-inactivated EIEC, with only TLR5 expression being the same (figure 4A). After $24 \mathrm{~h}$, the differences in TLR mRNA expression induced by viable and heat-inactivated EIEC were less marked, with TLR4 expression resulting in a higher response to heat-inactivated EIEC than viable EIEC (figure 4B).

After $6 \mathrm{~h}$ with heat-inactivated probiotic bacteria TLR2, TLR3, TLR7 and TLR9 expression was virtually undetectable and TLR1, TLR4 and TLR5 expression did not significantly differ from basal (figure 4C). After $24 \mathrm{~h}$, TLR2 expression remained lower than basal $(-3.3 \pm 0.1$-fold decrease vs basal; $\mathrm{p}<0.01)$, while TLR4 expression was significantly increased $(+3.0 \pm 0.2$-fold increase vs basal; $\mathrm{p}<0.01)$ (figure 4D). The analysis of differences between viable and heath-inactivated LP F19 showed that, as for EIEC, after 6 h there was a marked difference between viable and heath-inactivated bacteria that trended to be less evident after $24 \mathrm{~h}$ (figure 4C,D).

\section{Different TLR mRNA expression induced by bacterial-derived soluble factors}

After $6 \mathrm{~h}$ challenge with EIEC-derived soluble factors, TLR7 $(+3.5 \pm 0.7$-fold increase vs basal; $\mathrm{p}<0.01)$ and TLR9 $(+12.1 \pm 2.9$-fold increase vs basal; $\mathrm{p}<0.01)$ mRNA expression was significantly upregulated compared to the basal condition (figure 4A). After $24 \mathrm{~h}$, EIEC-derived soluble factors induced the upregulation of TLR7 $(+5.8 \pm 1.6$-fold increase vs basal; $p<0.01)$ and TLR9 $(+6.9 \pm 1.1$-fold increase vs basal; $\mathrm{p}<0.01) \mathrm{mRNA}$ (figure 4B).

With LP F19-derived soluble factors, after $6 \mathrm{~h}$, TLR2 mRNA was undetectable, TLR7 $(+4.6 \pm 0.8$-fold increase vs basal; $\mathrm{p}<0.01)$ and TLR9 $(+5.4 \pm 1.3$-fold increase vs basal; $\mathrm{p}<0.01)$ mRNA was significantly upregulated compared to the basal condition (figure 4C). After $24 \mathrm{~h}$, we observed a significant upregulation of TLR7 $(+5.7 \pm 1.6$-fold increase vs basal; $\mathrm{p}<0.01)$ and TLR9 (+12.2 \pm 2.9 -fold increase vs basal; $\mathrm{p}<0.01)$ mRNA, compared to the basal condition (figure 4D).

\section{TLR protein expression in EGC induced by viable bacteria}

Immunofluorescence shows that TLR 2 protein was not, or only barely, expressed in basal conditions but it was induced by both LP F19 and EIEC after $24 \mathrm{~h}(+22.8 \pm 5.6$ and $+11.8 \pm 3.2$-fold increase vs basal, respectively; $\mathrm{p}<0.05$ ) (figure $5 \mathrm{~A}, \mathrm{~B}$ ). We also performed western blot analysis, normalising data on the enteroglial marker GFAP, and we observed that TLR2 expression was very low in basal conditions, data consistent with
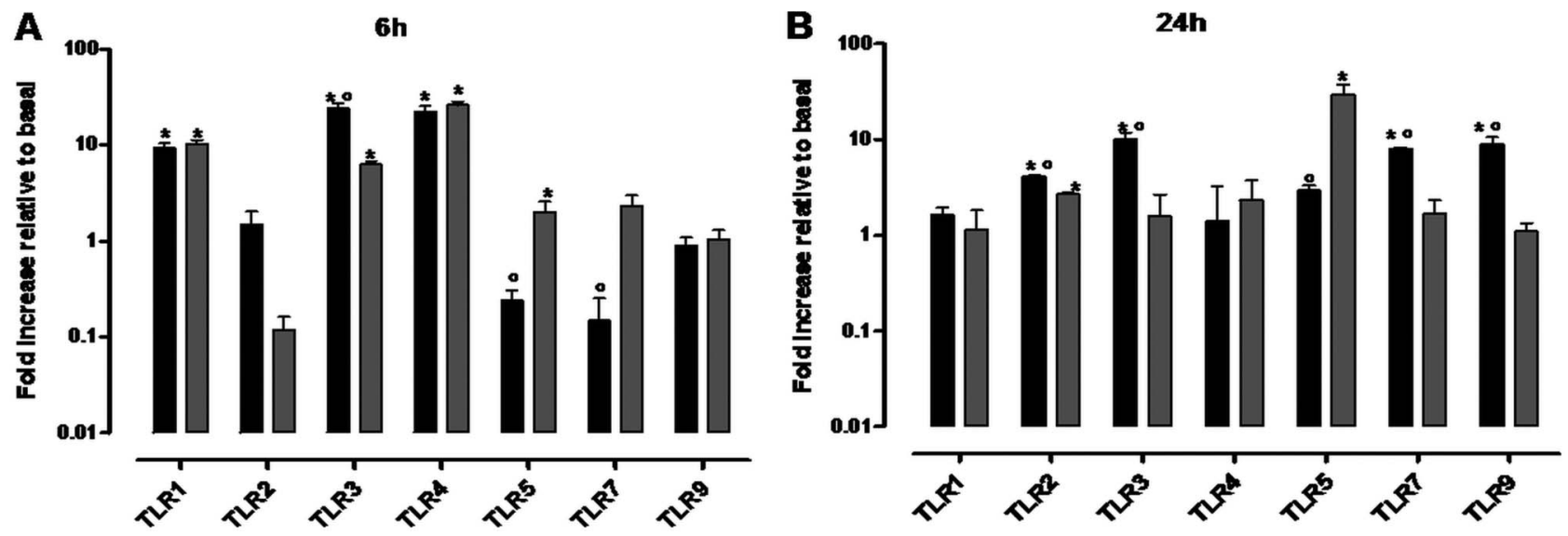

Figure 3 Modulation of Toll-like receptor (TLR) expression induced by viable enteroinvasive Escherichia coli (EIEC) and Lactobacillus paracasei ssp. paracasei F19 (LP F19). (A) Differences in TLR expression between viable EIEC (black bars) and viable LP F19 (grey bars) after 6 h of exposure. (B) Differences in TLR expression between viable EIEC (black bars) and viable LP F19 (grey bars) after $24 \mathrm{~h}$ of exposure. Normalised fold expression of each TLR were estimated by determining the $\Delta \Delta \mathrm{C}_{\mathrm{T}}\left(\Delta \mathrm{C}_{\mathrm{T} \text { TREATMENT }}-\Delta \mathrm{C}_{\mathrm{T} \text { CONTROL }}\right.$ ). Data are expressed in a logarithmic scale as a fold increase compared to controls (cells with medium alone). Each bar shows the mean $\pm S D$ of $n=5$ independent determinations. ${ }^{*} p<0.01$ (vs basal); ${ }^{\circ} p<0.01$ (EIEC vs LP F19). Scale bars: $100 \mu \mathrm{m}$. 
A

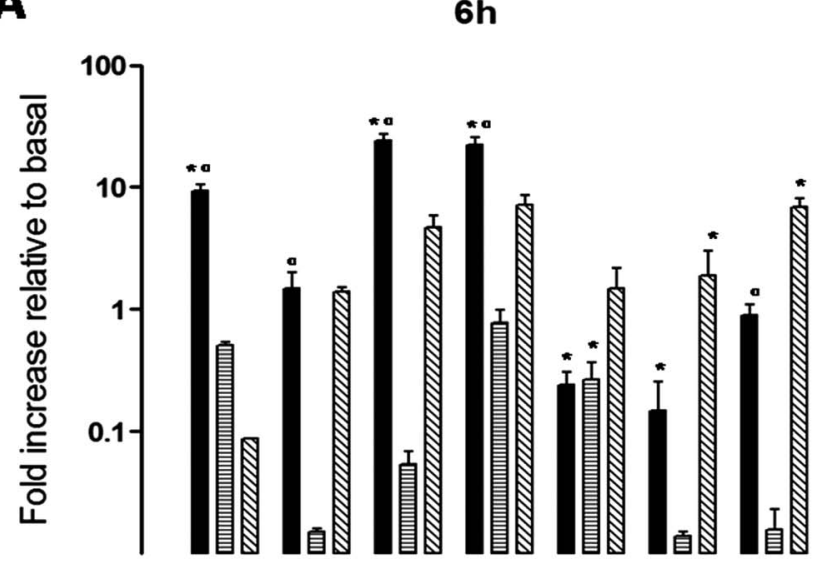

TLR1 TLR2 TLR3 TLR4 TLR5 TLR7 TLR9

C

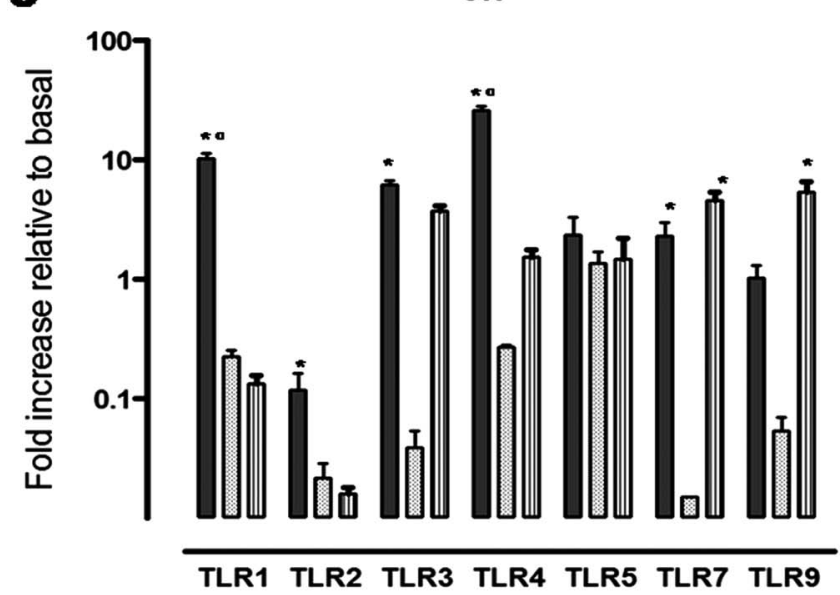

B

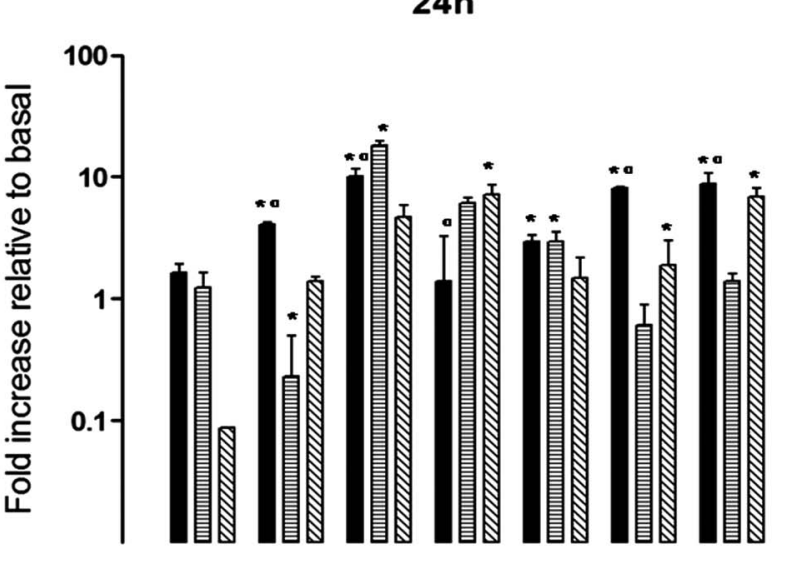

TLR1 TLR2 TLR3 TLR4 TLR5 TLR7 TLR9

D

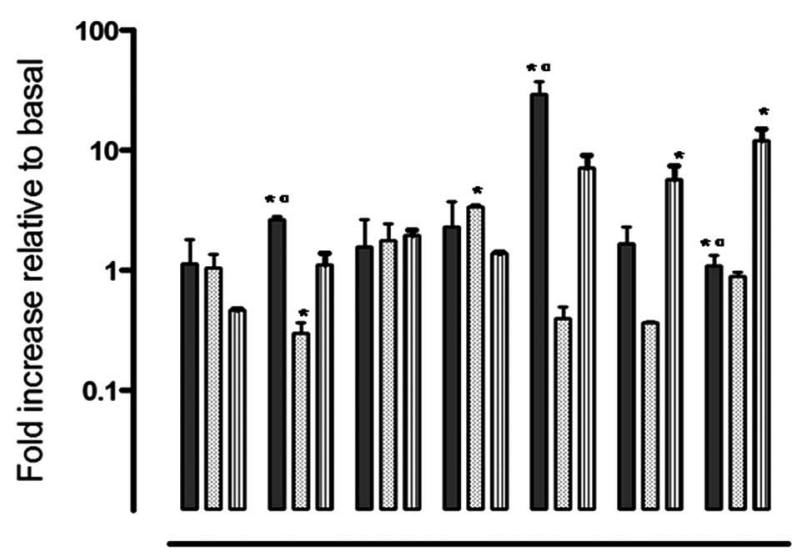

TLR1 TLR2 TLR3 TLR4 TLR5 TLR7 TLR9

Figure 4 Effect of viable bacteria, heat-inactivated bacteria and bacterial-derived soluble factors on Toll-like receptor (TLR) expression in enteric glial cells. (A) Differences in TLR expression between viable enteroinvasive Escherichia coli (EIEC) (black bars), heat-inactivated (white bars with horizontal lines) and ElEC-derived soluble factors (white bars with diagonal lines) after $6 \mathrm{~h}$ of exposure and (B) after $24 \mathrm{~h}$ of exposure. (C) Differences in TLR expression between viable Lactobacillus paracasei ssp. paracasei F19 (LP F19) (grey bars), heat-inactivated LP F19 (white bars with dots) and LP F19-derived soluble factors (white bars with vertical lines) after $6 \mathrm{~h}$ of exposure and (D) after $24 \mathrm{~h}$ of exposure. Data are expressed in a logarithmic scale as fold increase compared to basal conditions (cells with medium alone). Each bar shows the mean \pm SD of $n=5$ independent determinations. ${ }^{*} \mathrm{p}<0.01$ (vs basal); ${ }^{\circ} \mathrm{p}<0.01$ (vs heat-inactivated bacteria).

immunocytochemistry and mRNA expression analysis. Both pathogens and probiotics induced a significant upregulation of the TLR2 protein $(+96 \% \pm 6.5$ and $+80 \pm 3.3$ increase vs basal, respectively; $\mathrm{p}<0.05)$ that was not revealed at the mRNA level (figure 5C).

Despite the relatively robust expression at the mRNA level, EGC did not express high levels of TLR3 protein at baseline, after $24 \mathrm{~h}$. Both pathogens and probiotics induced a significant upregulation of TLR3 protein expression, as revealed by fluorescence $(+5.5 \pm 0.8$ and $+6.4 \pm 1.0$-fold increase vs basal; $\mathrm{p}<0.05)$ and western blot $(+78.1 \pm 6.6$ and $+120.0 \% \pm 10.3$ increase vs basal; $\mathrm{p}<0.01$ ) (figure 6).

Consistent with our findings on mRNA expression, after $24 \mathrm{~h}$, TLR4 levels were relatively high in basal conditions and both LP F19 and EIEC were unable to induce significant differences in protein expression, as revealed by fluorescence quantisation $(-0.65 \pm 0.1$ and $-0.61 \pm 0.2$-fold decrease vs basal; $p=N S)$ and western blot analysis $(-19 \% \pm 5.2$ and $-6 \% \pm 3.5$-fold increase vs basal; $\mathrm{p}=\mathrm{NS}$ ) (figure 7).

TLR2, TLR3 and TLR4 positivity was specifically localised and restricted to EGC (GFAP and S100B-positive cells) (figures
$5 \mathrm{~A}, 6 \mathrm{~A}$ and $7 \mathrm{~A})$. Although it is reported that TLR expression has usually been shown to be located to the plasma membrane and Golgi-associated vesicles, differences exist depending on cell types and their differentiation state. Here we show that, in EGC, TLR2 is detected mainly in the cytoplasm and in the plasma membrane while for TLR3 and TLR4 the majority label appears to be cytosolic and nuclear (Figures 5A, 6A and 7A).

After $6 \mathrm{~h}$, TLR protein expression on EGC was very low and not quantifiable (data not shown).

\section{TLR-dependent NF-кB activation in EGC}

Compared to basal conditions, western blot analysis of EGC nuclear protein extract revealed that EIEC, but not LP F19,

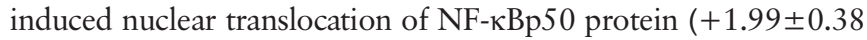
and $+0.56 \pm 0.19$-fold increase vs basal; $\mathrm{p}<0.05$ ) (figure $8 \mathrm{~A}$ ). Also TLR2, TLR3 and TLR4 agonists induced a significant upregulation of nuclear NF-kBp50 expression $(+1.65 \pm 0.33,+2.03$ $\pm 0.56,+1.79 \pm 0.39$-fold increase vs basal; $\mathrm{p}<0.05$ ) (figure $8 \mathrm{~A}$ ). When EGC were treated with the specific MyD88-blocking peptide, TLR2 and TLR4 agonists failed to induce NF-kBp50 nuclear translocation significantly (figure $8 \mathrm{~B}$ ). Only the TLR3 


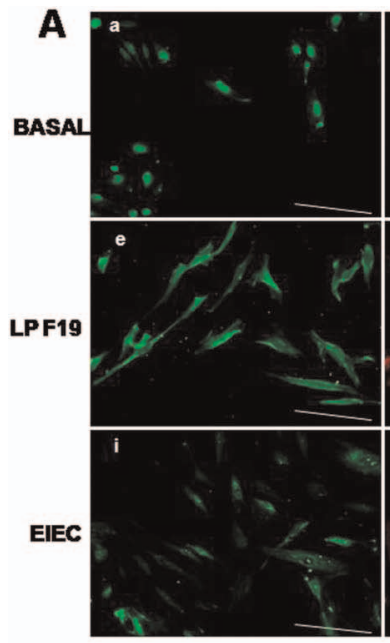

S100B

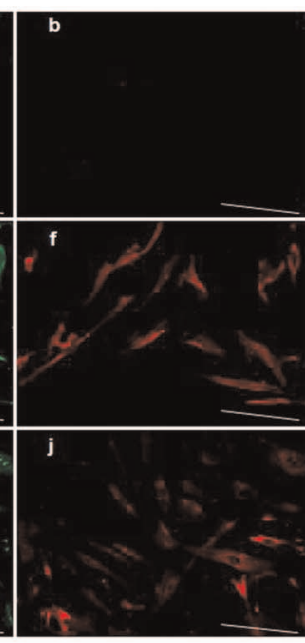

TUR2

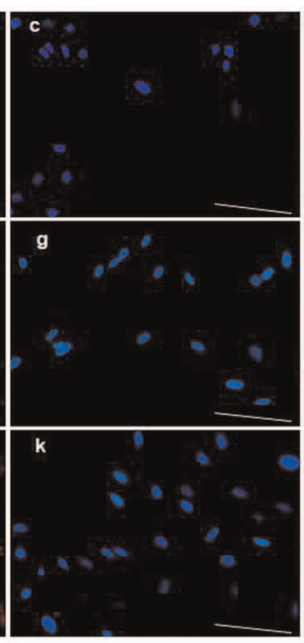

HOECHST

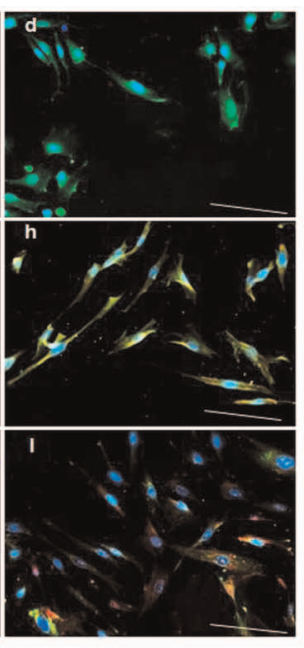

MERGE
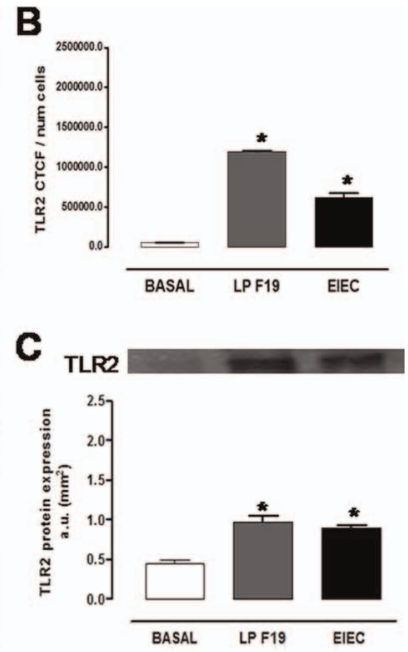

Figure 5 Toll-like receptor 2 (TLR2) protein expression in enteric glial cells (EGC). (A) Immunofluorescence staining showing that in basal conditions TLR2 protein was not expressed (b) while both Lactobacillus paracasei ssp. paracasei F19 (LP F19) (f) and enteroinvasive Escherichia coli (EIEC) (j) induced TLR2 protein expression. The nuclei were stained with Hoechst $(c, g, k)$. Panel $d, h$, l: merged. The pictures are representative of $\mathrm{n}=3$ independent immunofluorescence assays. Scale bars: $100 \mu \mathrm{m}$. (B) TLR2 corrected total cell fluorescence normalised on the number of cells of the field. (C) Western blot analysis showing the protein expression of TLR2 in stimulated compared to unstimulated EGC. The expression of TLR2 in cell homogenates is shown in the upper panel, whereas the densitometric analysis of corresponding bands is represented in the graph and is expressed as $\mathrm{mm}^{2}$ (arbitrary units). TLR2 expression has been normalised on the expression of the glial marker glial fibrillary acidic protein. The upper panel is representative of $n=4$ experiments. Each bar shows the mean $\pm S D$ of $n=4$ independent experiments. ${ }^{*} p<0.05$ versus basal.

agonist significantly increased NF-kBp50 nuclear protein expression $(+1.75 \pm 0.33$-fold increase vs basal; $\mathrm{p}<0.05$ (figure $8 \mathrm{~B}$ ). Figure 9 shows TLR2, TLR3 and TLR4 expression induced by their respective agonists.

\section{Bacterial-induced S100B protein expression and NO production}

After 24 h-exposure to the viable bacteria, we found that S100B protein expression was significantly higher in response to EIEC than to LP F19 compared to basal conditions (+2.9 \pm 0.2 -fold increase and $+1.1 \pm 0.3$-fold increase vs basal; $\mathrm{p}<0.01$ ) (figure 10A). Similarly, EIEC induced a significantly higher NO release than LP F19 compared to basal conditions (13.9 \pm 3.7 and $2.3 \pm 1.1 \mathrm{nmol} / 10^{6}$ cells vs $2.2 \pm 1.0 \mathrm{nmol} / 10^{6}$ of control cells; $\mathrm{p}<0.01$ ) (figure 10B). S100B protein expression and NO release induced by both heat-inactivated EIEC and LP F19 and by bacterial-derived soluble factors were not significantly different compared to basal conditions (data not shown).

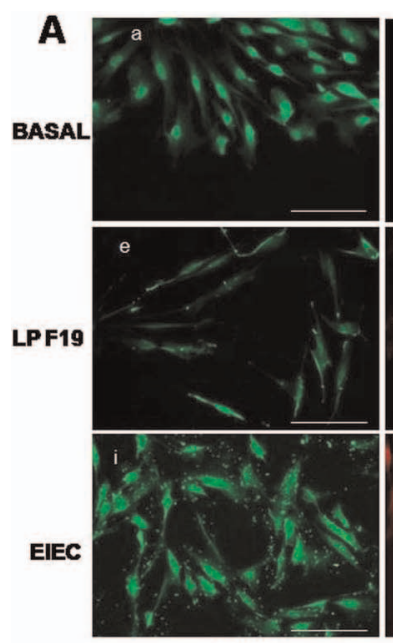

GFAP
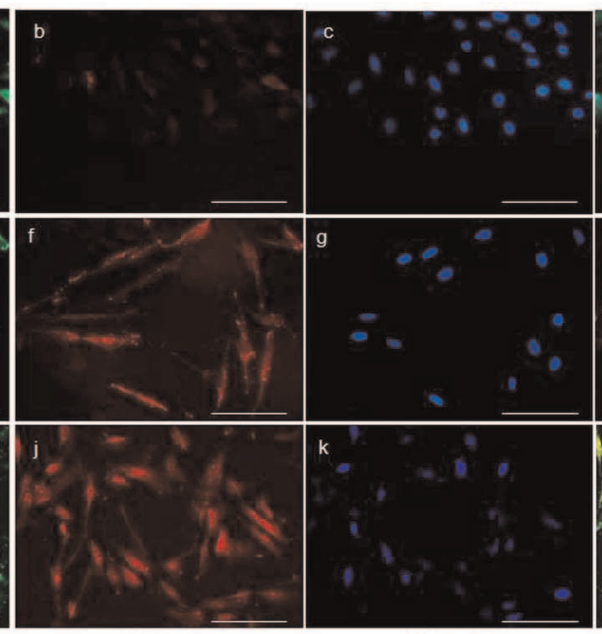

TLR3

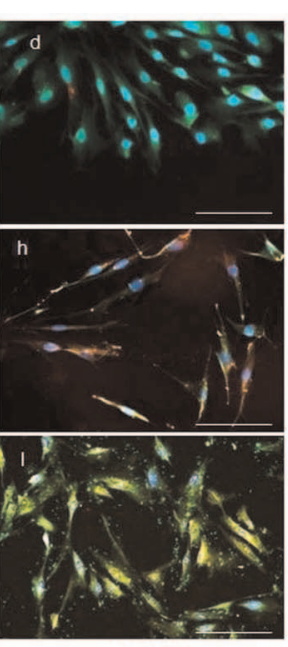

MEREE
B

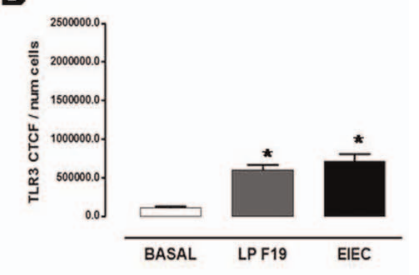

C

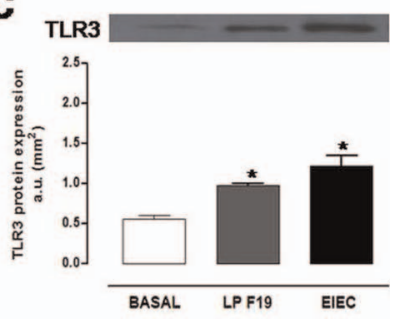

Figure 6 Toll-like receptor 3 (TLR3) protein expression in enteric glial cells (EGC). (A) Immunofluorescence staining showing that TLR3 protein was weakly expressed under basal conditions (b) while both Lactobacillus paracasei ssp. paracasei F19 (LP F19) (f) and enteroinvasive Escherichia coli (EIEC) (j) induced TLR2 protein expression. The nuclei were stained with Hoechst $(c, g, k)$. Panel $d, h$, l: merged. The pictures are representative of $\mathrm{n}=3$ independent immunofluorescence assays. Scale bars: $100 \mu \mathrm{m}$. (B) TLR3 corrected total cell fluorescence normalised on the number of cells of the field. (C) Western blot analysis showing protein expression of TLR3 in stimulated compared to unstimulated EGC. The expression of TLR3 in cell homogenates is shown in the upper panel, whereas the densitometric analysis of the corresponding bands is represented in the graph and is expressed as $\mathrm{mm}^{2}$ (arbitrary units). TLR3 expression has been normalised on the expression of the glial marker glial fibrillary acidic protein (GFAP). The upper panel is representative of $n=4$ experiments. Each bar shows the mean $\pm S D$ of $n=4$ independent experiments. ${ }^{*} p<0.05$ versus basal. 


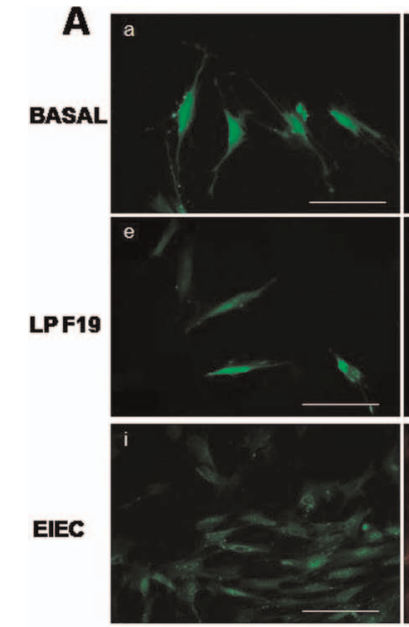

$\mathbf{s 1 0 0 B}$
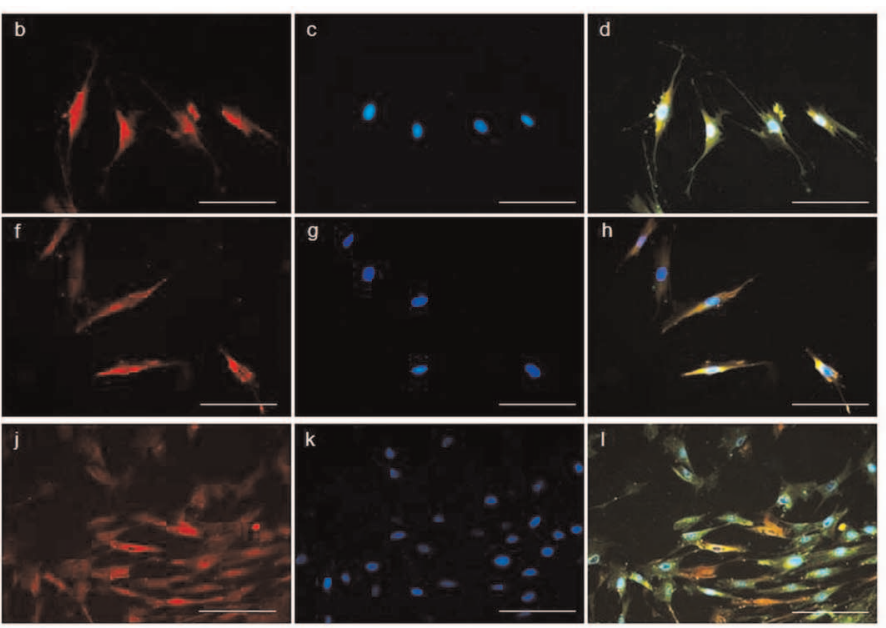

TRA

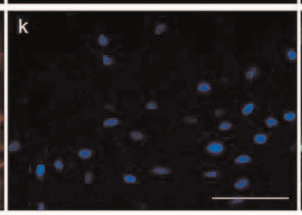

HOECHST

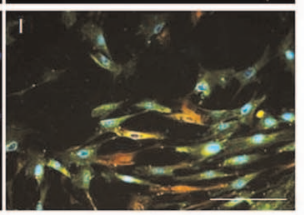

MPRGE

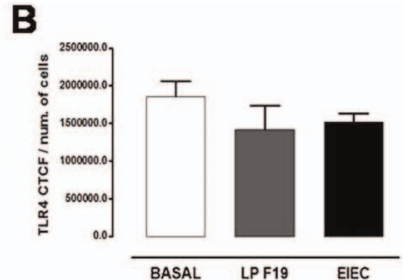

C

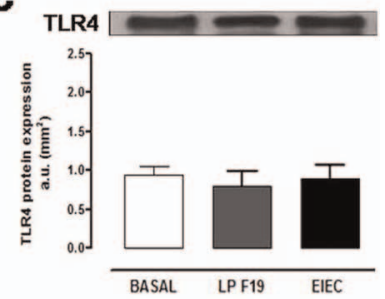

Figure 7 Toll-like receptor 4 (TLR4) protein expression in enteric glial cells (EGC). (A) Immunofluorescence staining showing that in basal conditions TLR4 protein was expressed (b) and neither Lactobacillus paracasei ssp. paracasei F19 (LP F19) (f) nor enteroinvasive Escherichia coli (EIEC) (j) were able to induce a significant increase in TLR4 protein expression. The nuclei were stained with Hoechst $(c, g, k)$. Panel d, h, l: merged. Pictures are representative of $n=3$ independent immunofluorescence assays. Scale bars: $100 \mu \mathrm{m}$. (B) TLR4 corrected total cell fluorescence normalised on the number of cells of the field. (C) Western blot analysis showing protein expression of TLR4 in stimulated compared to unstimulated EGC. The expression of TLR4 in cell homogenates is shown in the upper panel, whereas the densitometric analysis of corresponding bands is represented in the graph and is expressed as $\mathrm{mm}^{2}$ (arbitrary units). TLR2 expression has been normalised on the expression of the glial marker glial fibrillary acidic protein (GFAP). The upper panel is representative of $n=4$ experiments. Each bar shows the mean $\pm S D$ of $n=4$ independent experiments.

\section{Effect of anti-S100B, anti-RAGE and anti-MyD88 on $\mathrm{S} 100 \mathrm{~B}$ protein expression and NO production}

EIEC-induced S100B upregulation was associated with NO production, because preincubation with the specific S100B-blocking antibody, added $2 \mathrm{~h}$ before exposure to EIEC, impaired NO release from EGC $(+1.0 \pm 0.3$-fold increase vs basal; $\mathrm{p}=\mathrm{NS})$ (figure 10C). As expected, the same result was obtained by treating EGC for $2 \mathrm{~h}$ with the specific RAGE-blocking antibody $(+1.1 \pm 0.3$-fold increase vs basal; $\mathrm{p}=\mathrm{NS}$ ) (figure 10C). To evaluate whether the TLR pathway was also involved in NO release, EGC were preincubated with the specific MyD88-blocking peptide and, similarly to anti-S100B and anti-RAGE, this condition led to impaired NO production (1.1 \pm 0.4 -fold increase vs basal; $\mathrm{p}=\mathrm{NS}$ ) (figure 10C). Neither anti-S100B, anti-RAGE nor anti-MyD88 affected EIEC-induced S100B protein expression (data not shown). This suggests the presence of a common pathway linking S100B, RAGE and MyD88, a downstream signal characteristic of all TLR, with the exception of TLR3.

\section{DISCUSSION}

Various studies in animal models have greatly contributed to elucidate EGC functions, indicating that these cells are involved in the regulation of intestinal pathophysiological events. ${ }^{2-7} 141517$ However, only a few studies have translated the data obtained from animal models to humans. Here, we describe a novel and potentially important function of human EGC, highlighting their ability to be activated and to interact with bacteria, thus playing an active role in host-bacteria crosstalk. We also show how enteroglial-derived S100B protein is able to integrate the TLR signalling involved in NO release.

We recently demonstrated that human EGC are activated by exogenous stimuli. ${ }^{14}{ }^{15}{ }^{17}$ In the present study, we provide evidence that EGC are also activated by invading microorganisms, such as enteroinvasive bacteria, and that this activation induces the expression of MHC-II and cFos proteins. These data confirm previous observations suggesting that EGC may interact with bacteria, ${ }^{67}$ and point out the role of EGC in the regulation of the host-bacteria interplay also in humans.

Innate immunity in the brain is controlled primarily by TLR expressed on glial cells, especially astrocytes and microglia. In healthy conditions, astrocytes barely express TLR, but their expression is rapidly upregulated following bacterial invasion. ${ }^{36}$ We observed that EGC share with astrocytes the potential role of resident immune sentinels, as they express TLR at baseline, although only TLR3 3 and TLR5 mRNA were expressed at the intermediate level, while basal expression of other TLR was very low. These findings indicate that EGC, together with the ability to be activated by exogenous insults and bacteria, also possess the molecular mechanisms potentially able to trigger innate immunity in the gut.

In order to gain more mechanistic insights into TLR response and to evaluate whether TLR expression on EGC is modulated by bacteria, we set up a co-culture model of EGC bacteria. Our data showed that TLR mRNA expression is differentially modulated by pathogens and probiotics. Together with gene expression, we also demonstrated protein expression of TLR2, TLR3 and TLR4. TLR2 and TLR4 basal protein expression was consistent with mRNA levels, while despite a relatively robust basal mRNA expression, TLR3 protein expression was very low. The reasons for the lack of correlation between mRNA and protein expression are unclear but, as proposed by other studies, ${ }^{37} 38$ this may indicate the presence of post-translational mechanisms for the regulation of protein abundance. We also showed that protein expression of TLR2 and TLR3 can be differentially modulated by pathogens and probiotics. Indeed, LP F19 induced higher TLR2 expression than EIEC, while TLR3 expression is higher in response to EIEC than to LP F19. This is consistent with data from the literature, because TLR2 detects mainly Gram-positive bacteria, ${ }^{30}$ while TLR3, in astrocytes, is upregulated in response to bacterial products. ${ }^{39}$ This differently induced TLR expression may indicate the heterogeneity of cellular response to pathogens or probiotics, suggesting that in human EGC the mechanisms of bacterial recognition are tailored to the 


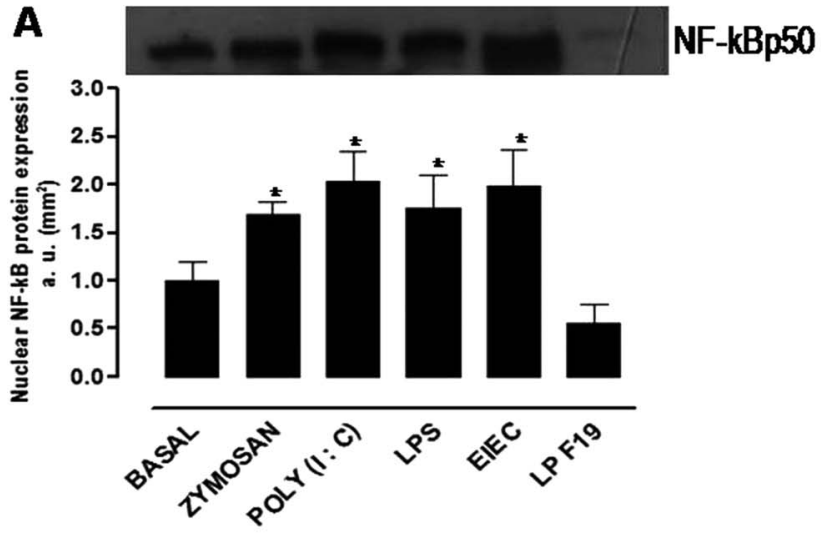

B

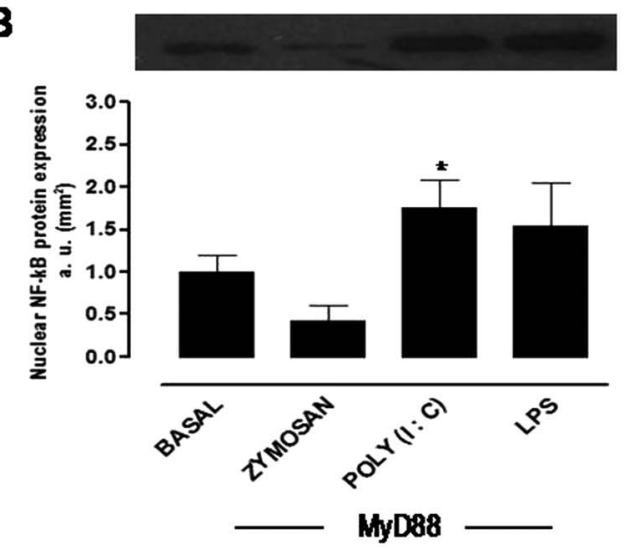

Figure 8 Nuclear factor $\kappa B(N F-\kappa B) p 50$ expression in nuclear lysates from enteric glial cells (EGC). (A) Western blot analysis showing that $\mathrm{NF}-\kappa \mathrm{Bp} 50$ protein expression is significantly upregulated in response to Toll-like receptor (TLR) agonists and enteroinvasive Escherichia coli (EIEC) but not to Lactobacillus paracasei ssp. paracasei F19 (LP F19). (B) Western blot analysis showing that: TLR2 agonist zymosan failed to induce NF- $\kappa \mathrm{Bp} 50$ expression when EGC were preincubated with MyD88; TLR3 agonist poly (I:C) significantly upregulated NF- $\kappa B$ expression compared to unstimulated EGC; TLR4 agonist lipopolysaccharide (LPS) induced a non-significant upregulation of NF- $\kappa$ Bp50 expression. Upper panels show NF- $\kappa B$ in nuclear homogenates and are representative of $n=3$ experiments. The graphs show the densitometric analysis (arbitrary units) and are representative of $n=3$ experiments. ${ }^{*} p<0.05$ versus basal.

type of bacteria involved. TLR expression may also be influenced by the diverse localisation of the bacteria, as EIEC, on infection, has intracellular localisation, ${ }^{40}$ while probiotic strain localisation is extracellular. ${ }^{41}$ In addition, heat-inactivated bacteria were also able to modulate TLR mRNA expression differently, although to a lesser extent than viable bacteria. The data on heat-inactivated bacteria indicate that EIEC and LP F19 effects on EGC are not only mediated by soluble factors. Soluble factors have their importance in modulating TLR mRNA expression because data obtained after treatment with pathogen or probiotic-derived soluble factors show different TLR expression, compared to basal conditions and to live bacteria. Based on these results, it would be of extreme interest to determine which bacterial structural components or which released soluble factors are able to induce a TLR-mediated response in human EGC.

In order to prove the effective functionality of TLR on EGC, we analysed the protein expression of NF- $\mathrm{KB}$, which is considered the main effector of TLR activation. ${ }^{30}$ We found that TLR2, TLR3 and TLR4 agonists were able to induce NF-кBp50 nuclear translocation in EGC. Consistent with the literature, we provided evidence that by inhibiting MyD88, an important mediator of almost all the TLR downstream signalling, the TLR2 agonist failed to induce NF-кBp50 expression and the TLR4 agonist induced only a weak, not significant, NF-кBp50 expression. As TLR3 signalling is MyD88-independent, the TLR3 agonist (Poly $\mathrm{I}$ :C) was able to induce NF-kBp50 expression in EGC significantly.

Sensing the presence of pathogens to mount the effective response is the main role of TLR. TLR activation, via iNOS induction, leads to increased NO production. ${ }^{11}{ }^{12}$ In our previous works, we observed increased NO release when EGC were challenged with bacterial lipopolysaccharide. ${ }^{13} 14$ NO production was correlated with the upregulation of enteroglial-derived S100B protein. The data presented here show that S100B protein expression is also upregulated when EGC are challenged with pathogenic EIEC, but not with probiotic LP F19. This upregulation was related to the increased NO production from EGC. Indeed, as expected, blocking S100B with the specific antibody resulted in impaired EIEC-induced NO production.

Given the fact that both S100B and TLR-mediated pathways lead to NO production, we have addressed the issue of whether and how the two systems interact. A major finding of this study suggests that S100B is able to integrate TLR signalling in EGC. As reported in the literature, S100B exerts many effects by interacting with the multiligand receptor RAGE. ${ }^{42} 43$ When RAGE was blocked with the specific antibody, NO production was impaired. However, and most interestingly, we provide evidence that the inhibition of MyD88, an important mediator of almost all the TLR downstream signalling, also resulted in impaired NO production, without affecting S100B expression. As RAGE is also associated with the TLR pathway, ${ }^{16}$ these findings suggest that RAGE may act as a molecular link between the S100B and TLR pathways, which, once activated, leads to NO production from EGC. We can speculate that when a specific insult (ie, lipopolysaccharide or a pathogenic bacteria) upregulates S100B expression, this protein interacts with RAGE, which is expressed on the surface of EGC. As proposed by other studies, the S100B/RAGE complex may be internalised within the cell and, ${ }^{43}$ here, interact, directly or not, with MyD88, thus inducing iNOS expression and NO release. This suggestive hypothesis needs to be confirmed by further investigations. Nonetheless, these preliminary data confirm the role of the enteroglial-derived S100B protein as an active player in host-bacteria interaction.

In summary, in this study we demonstrated, for the first time, that human-derived EGC express TLR and directly interact with bacteria. The potential role of EGC in triggering innate immune responses is emphasised by the demonstration that these cells not only express TLR, but are able to discriminate between pathogens and probiotics by modulating TLR expression. Our data show that EGC adequately respond to bacterial insults (ie, releasing NO) and, possibly, they play a role in modulating nitrosative stress. NO release from EGC involves both S100B and TLR-mediated pathways, and the interference with these targets might be an efficient therapeutic strategy to modulate abnormal NO production within the gut. In addition, we showed that TLR expression in EGC is specifically regulated by the type of bacteria interacting with them, and that NO production consequent to such contact depends on both TLR and S100B \RAGE involvement, suggesting the presence of a novel common pathway leading to NO production. This study lays the basis to further considering EGC as active participants in host-bacteria crosstalk. 


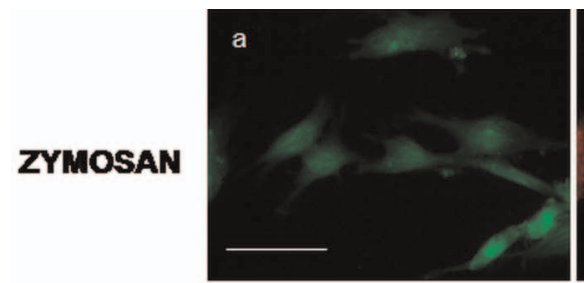

S100B

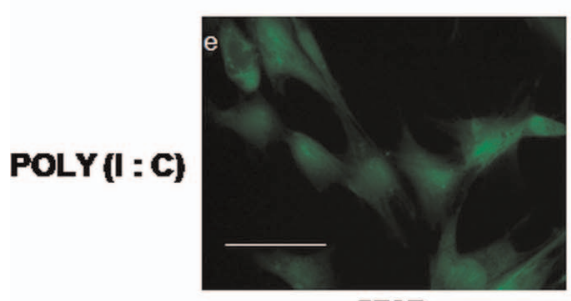

GFAP

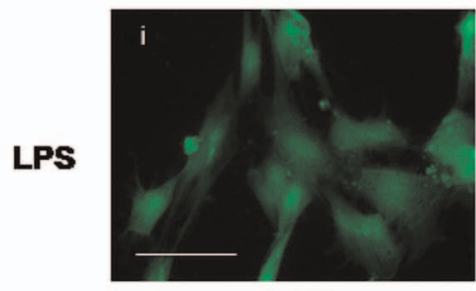

$\mathbf{s 1 0 0 B}$

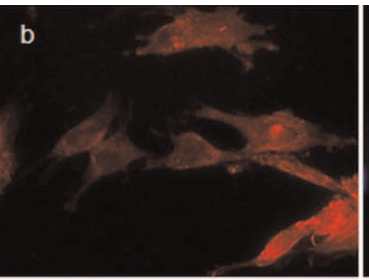

TLR2

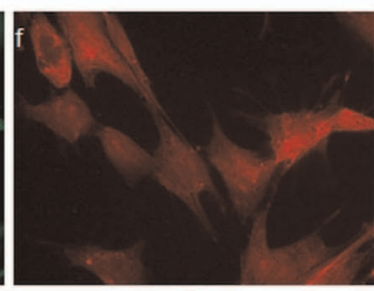

TLR3

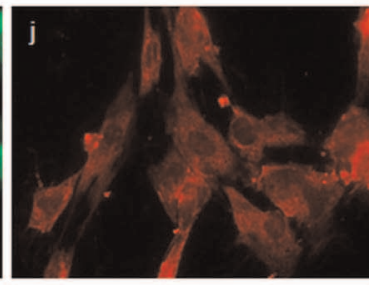

TLR4

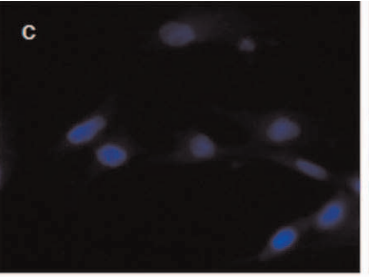

HOECHST

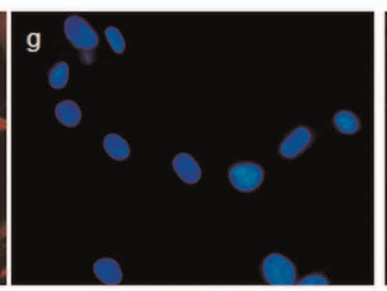

HOECHST

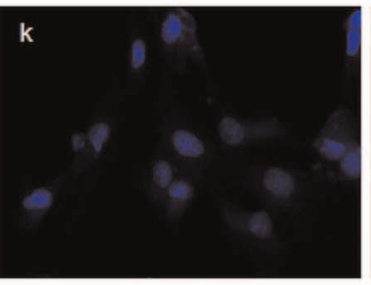

HOECHST

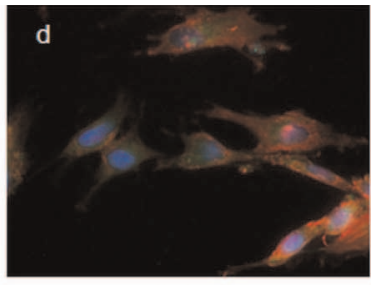

MBRED

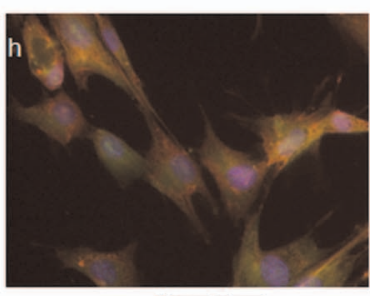

MBRED

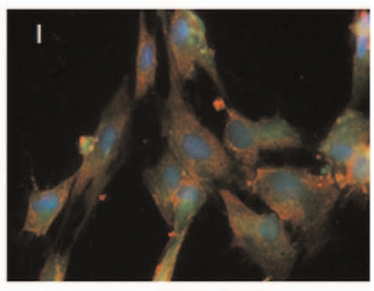

MPRED

Figure 9 Toll-like receptor (TLR) expression in enteric glial cells (EGC) induced by TLR agonists. Immunofluorescence staining showing: S100B (a) and TLR2 (b) expression induced by TLR2 agonist zymosan; glial fibrillary acidic protein (GFAP) (e) and TLR3 (f) expression induced by TLR3 agonist poly (I:C). S100B (i) and TLR2 (j) expression induced by TLR4 agonist lipopolysaccharide. Nuclei were stained with Hoechst (c, g, k). Panel d, h, l: merged. Pictures are representative of $n=3$ independent immunofluorescence assays. Scale bars: $40 \mu \mathrm{m}$.

Based on our present results and previous studies, ${ }^{4-7}$ it could be of extreme interest to translate these observational data into animal models, in order to determine whether the modulation of TLR receptors and the regulation of $\mathrm{NO}$ production observed in vitro also exist in vivo.
In conclusion, although further studies are required to define better the role of EGC in the host-bacteria interaction and the exact mechanisms involved in NO production, our findings highlight a novel role for EGC, demonstrating that they differentially sense the presence of harmful or healthy bacteria in the gut.
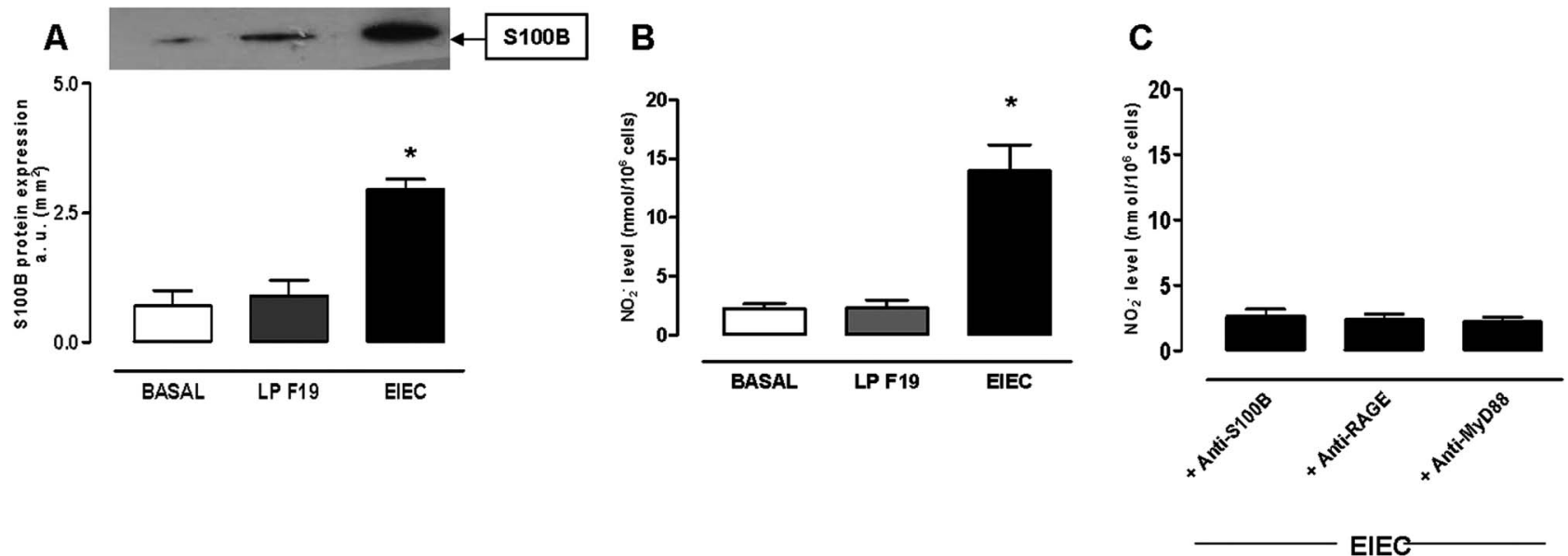

Figure 10 S100B expression and nitric oxide (NO) production induced by bacteria. (A) Western blot analysis showing that S100B protein expression is significantly upregulated in response to enteroinvasive Escherichia coli (EIEC) but not in response to Lactobacillus paracasei ssp. paracasei F19 (LP F19). The upper panel shows S100B in cell homogenates, and is representative of $n=3$ experiments. The graph shows densitometric analysis (arbitrary units). ${ }^{*} \mathrm{p}<0.01$ versus basal. (B) The analysis of nitrite levels revealed that EIEC, but not LP F19, significantly increased NO production in EGC. NO production was determined by measuring the accumulation of nitrite in the culture medium of $24 \mathrm{~h}$ EGC bacteria cultures. Each bar shows the mean $\pm S D$ of $n=10$ experiments. ${ }^{*} p<0.01$ versus basal. (D) EIEC stimulation for $24 \mathrm{~h}$ failed to increase NO production when EGC were preincubated with anti-S100B antibody, anti-receptor for advanced glycation endproducts antibody or anti-MyD88 blocking peptide, respectively. Each bar shows the mean \pm SD of $n=10$ independent experiments. 
Contributors FT: contributed to the conception, experimental work, analysis and interpretation of the data, and the draft of the manuscript; CC: contributed to the experimental work and critical revision of the manuscript; GS contributed to the conception, interpretation of the data, and the draft of the manuscript; IP, FDG, $A D A, M C$ and MG: contributed to the critical revision of the manuscript; RC: contributed to the conception, interpretation of the data, draft, critical revision and final approval of the manuscript. The authors have all read and approved the manuscript.

Funding This research received a specific grant from the Italian Ministry of University and Research, COFIN project no 2009HLNNRL.

Competing interests None.

Ethics approval All procedures were approved by the ethics committee of the 'Federico II' University of Naples (protocol no 106/2010).

Patient consent Obtained.

Provenance and peer review Not commissioned; externally peer reviewed.

\section{REFERENCES}

1 Sekirov I, Russel SL, Antunes CM, et al. Gut microbiota in health and disease. Physiol Rev 2010;90:859-904.

2 Ruhl A, Trotter J, Stremmel W. Isolation of enteric glia and establishment of transformed enteroglial cell lines from the myenteric plexus of adult rat. Neurogastroenterol Motil 2001;13:95-106.

3 Lomax AE, Fernandez E, Sharkey KA. Plasticity of the enteric nervous system during intestinal inflammation. Neurogastroenterol Motil 2005;7:4-15.

4 Van Landeghem L, Mahé MM, Teusan R, et al. Regulation of intestinal epithelial cells transcriptome by enteric glial cells: impact on intestinal epithelial barrier functions. BMC Genomics 2009;2:507.

5 Savidge TC, Newman P, Pothoulakis C, et al. Enteric glia regulate intestinal barrier function and inflammation via release of S-nitrosoglutathione. Gastroenterology 2007;132:1344-58

6 Coron $\mathrm{E}$, Flamant M, Aubert $\mathrm{P}$, et al. Characterisation of early mucosal and neuronal lesions following Shigella flexneri infection in human colon. PLoS One 2009:4:e4713.

7 Flamant M, Aubert P, Rolli-Derkinderen $\mathrm{M}$, et al. Enteric glia protect against Shigella flexneri invasion in intestinal epithelial cells: a role for S-nitrosoglutathione. Gut 2011:60:473-84.

8 Constantinescu CS, Tani M, Ransohoff RM, et al. Astrocytes as antigen-presenting cells: expression of IL-12//L-23. J Neurochem 2005:95:331-40.

9 Bowman CC, Rasley A, Tranguch SL, et al. Cultured astrocytes express toll-like receptors for bacterial products. Glia 2003:43:281-91.

10 Barajon I, Serrao G, Arnaboldi F, et al. Toll-like receptors 3, 4, and 7 are expressed in the enteric nervous system and dorsal root ganglia. J Histochem Cytochem 2009:57:1013-23.

11 Kamijo R, Harada H, Matsuyama T, et al. Requirement for transcription factor IRF-1 in NO synthase induction in macrophages. Science 1994;263:1612-15.

12 Negishi $\mathrm{H}$, Fujita $\mathrm{Y}$, Yanai $\mathrm{H}$, et al. Evidence for licensing of IFN-gamma-induced IFN regulatory factor 1 transcription factor by MyD88 in Toll-like receptor-dependent gene induction program. Proc Natl Acad Sci USA 2006;103:15136-41.

13 Hibbs JB, Taintor RR, Vavrin Z, et al. Nitric oxide: a cytotoxic activated macrophage effector molecule. Biochem Biophys Res Commun 1988;157:87-94.

14 Esposito G, Cirillo C, Sarnelli G, et al. Enteric glial-derived S100B protein stimulates nitric oxide production in celiac disease. Gastroenterology 2007;133:918-25.

15 Cirillo C, Sarnelli G, Esposito G, et al. Increased mucosal nitric oxide production in ulcerative colitis is mediated in part by the enteroglial-derived S100B protein. Neurogastroenterol Motil 2009;21:1209-e112.

16 Tian J, Avalos AM, Mao SY, et al. Toll-like receptor 9-dependent activation by DNA-containing immune complexes is mediated by HMGB1 and RAGE. Nat Immunol 2007:8:487-96.

17 Cirillo C, Sarnelli G, Turco F, et al. Proinflammatory stimuli activates human-derived enteroglial cells and induces autocrine nitric oxide production. Neurogastroenterol Motil 2011;23:e372-82.

18 Sarnelli G, Vanden Berghe P, Raeymaekers $\mathrm{P}$, et al. Inhibitory effects of galanin on evoked [Ca2+]i responses in cultured myenteric neurons. Am J Physiol Gastrointest Liver Physiol 2004;286:G1009-14.
19 Cotmore SF, Crowhurst SA, Waterfield MD. Purification of Thy-1-related glycoproteins from human brain and fibroblasts: comparisons between these molecules and murine glycoproteins carrying Thy-1.1 and Thy-1.2 antigens. Eur J Immunol 1981;11:597-603.

20 Nataro JP, Kaper JB. Diarrheagenic Escherichia coli. Clin Microbiol Rev 1998;11:142-201.

21 Ljungh A, Lan J, Yanagisawa N. Isolation. Selection and characteristics of Lactobacillus paracasei subsp. paracasei F19. Microb Ecol Health Dis 2002:14:4-6.

22 Eriksen JL, Druse MJ. Astrocyte-mediated trophic support of developing serotonin neurons: effects of ethanol, buspirone, and S100B. Brain Res Dev Brain Res 2001;131:9-15.

23 Esposito G, Imitola J, Lu J, et al. Genomic and functional profiling of human Down syndrome neural progenitors implicates $\mathrm{S100B}$ and aquaporin 4 in cell injury. Hum Mol Genet 2008;17:440-57.

24 Scott M, Biliar T. $\beta 2$-integrin induced p38MAPK activation is a key mediator in the CD14/TLR4/MD2-dependent uptake of LPS by hepatocytes. J Biol Chem 2008;283:29433-46.

25 Casabianca A, Orlandi C, Fraternale A, et al. Development of a real-time PCR assay using SYBR Green I for provirus load quantification in a murine model of AIDS. J Clin Microbiol 2004;42:4361-4.

26 Dolganiuc A, Garcia C, Kodys K, et al. Distinct Toll-like receptor expression in monocytes and T cells in chronic HCV infection. World I Gastroenterol 2006;12:1198-204.

27 Nakamura Y, Kano R, Hasegawa A, et al. Interleukin-8 and tumor necrosis factor alpha production in human epidermal keratinocytes induced by Trichophyton mentagrophytes. Clin Diagn Lab Immunol 2002;9:935-7.

28 Livak KJ, Schmittgen TD. Analysis of relative gene expression data using real-time quantitative PCR and the 2(-delta delta $C(T)$ ) method. Methods 2001;25:402-8.

29 Jack CS, Arbour N, Manusow J, et al. TLR signaling tailors innate immune responses in human microglia and astrocytes. I Immun 2005;175:4320-30

30 Akira S, Takeda K. Toll-like receptor signalling. Nat Rev Immunol 2004;4:499-511.

31 Farina C, Krumbholz M, Giese T, et al. Preferential expression and function of Toll-like receptor 3 in human astrocytes. J Neuroimmunol 2005;159:12-19.

32 Jessen KR, Mirsky R. Glial cells in the enteric nervous system contain glial fibrillary acidic protein. Nature 1980;286:736-7.

33 Burgess A, Vigneron $S$, Brioudes $E$, et al. Loss of human Greatwall results in $G 2$ arrest and multiple mitotic defects due to deregulation of the cyclin B-Cdc2/PP2A balance. Proc Natl Acad Sci USA 2010;107:12564-69.

34 Coron E, Auksorius E, Pieretti A, et al. Full-field optical coherence microscopy is a novel technique for imaging enteric ganglia in the gastrointestinal tract. Neurogastroenterol Motil 2012;24:e611-e621.

35 Hoffman GE, Smith MS, Verbalis JG. c-Fos and related immediate early gene products as markers of activity in neuroendocrine systems. Front Neuroendocrinol 1993:14:173-213

36 Trudler D, Farfara D, Frenkel D. Toll-like receptor expression and signalling in glia cells in neuro-amyloidogenic diseases: towards future therapeutic application. Mediators Inflamm 2010;2010:pii 497987.

37 Gry M, Rimini R, Stromberg $\mathrm{S}$, et al. Correlation between RNA and protein expression profiles in 23 human cell line. BMC Genomics 2009;10:365.

38 Dunne A, O'Neill L. New insights into the post-translational modification of Toll-like receptor signaling molecules. J Endotoxin Res 2005;11:325-32.

39 Carpentier PA, Begolka WS, Olson JK, et al. Differential activation of astrocytes by innate and adaptive immune stimuli. Glia 2005;49:360-74.

40 Parsot C. Shigella spp. and enteroinvasive Escherichia coli pathogenicity factors. FEMS Microbiol Lett 2005:252:11-18.

41 Corthésy B, Gaskins HR, Mercenier A. Cross-talk between probiotic bacteria and the host immune system. J Nutr 2007;137(3 Suppl. 2):781S-90S.

42 Hofmann MA, Drury S, Fu C, et al. RAGE mediates a novel proinflammatory axis: a central cell surface receptor for S100/calgranulin polypeptides. Cell 1999:97:889-901.

43 Schmidt AM, Yan SD, Yan SF, et al. The multiligand receptor RAGE as a progression factor amplifying immune and inflammatory responses. I Clin Invest 2001; 108:949-55

44 Sbai O, Devi TS, Melone MA, et al. RAGE-TXNIP axis is required for S100B-promoted Schwann cell migration, fibronectin expression and cytokine secretion. J Cell Sci 2010;123:4332-9. 

bacteria-induced Toll-like receptor signalling in human enteric glial cells

Fabio Turco, Giovanni Sarnelli, Carla Cirillo, et al.

Gut published online January 3, 2013

doi: 10.1136/gutjnl-2012-302090

Updated information and services can be found at:

http://gut.bmj.com/content/early/2013/01/03/gutjnl-2012-302090.full.html

These include:

Data Supplement

"Supplementary Data"

http://gut.bmj.com/content/suppl/2013/01/05/gutjnl-2012-302090.DC1.html "Supplementary Data"

http://gut.bmj.com/content/suppl/2013/01/06/gutjnl-2012-302090.DC2.html

References This article cites 44 articles, 14 of which can be accessed free at: http://gut.bmj.com/content/early/2013/01/03/gutjnl-2012-302090.full.html\#ref-list-1

$\mathbf{P}<\mathbf{P} \quad$ Published online January 3, 2013 in advance of the print journal.

Email alerting Receive free email alerts when new articles cite this article. Sign up in service the box at the top right corner of the online article.

\section{Notes}

Advance online articles have been peer reviewed, accepted for publication, edited and typeset, but have not not yet appeared in the paper journal. Advance online articles are citable and establish publication priority; they are indexed by PubMed from initial publication. Citations to Advance online articles must include the digital object identifier (DOIs) and date of initial publication.

To request permissions go to:

http://group.bmj.com/group/rights-licensing/permissions

To order reprints go to:

http://journals.bmj.com/cgi/reprintform

To subscribe to BMJ go to:

http://group.bmj.com/subscribe/ 